\title{
LOS USOS ESTRATÉGICOS DE LA OBSERVACIÓN ELECTORAL. EL CASO DE LA ALIANZA CIIVICA EN MÉXICO (1994-2012)
}

\author{
TANia Navarro Rodríguez
}

El 13 DE ABRIL DE 2015, ${ }^{*}$ el diario mexicano Reforma denunció la intromisión de Leonel Sandoval, magistrado del Tribunal Superior de Justicia de Jalisco y padre del gobernador de este estado, en la campaña de su partido, el Revolucionario Institucional (PRI). ${ }^{1} R e-$ forma hizo público el contenido de una grabación en la que se oye al magistrado invitar a los militantes a movilizarse para "reclutar por lo menos dos observadores electorales por casilla" para obtener información sobre los votantes y darla a los promotores del voto el día de la elección. El magistrado reconoce el carácter ilegal de esa acción, pero prosigue al decir que "por eso, no lo vamos a estar diciendo". Más adelante en la grabación, el responsable de los "observadores electorales del PRI de Jalisco" declara que él ya habló con las autoridades del Instituto Electoral y de Participación Ciudadana de Jalisco (IEPCJ) y del Instituto Nacional Electoral (INE) y asegura que están dispuestos a apoyar al partido de ese estado. ${ }^{2}$ Las acusaciones contra Leonel Sandoval, el PRI y su hijo, no se hacen esperar: asociaciones y partidos de oposición interponen diversos

* Agradezco calurosamente los comentarios de Julie Minoc y de los dictaminadores anónimos a las versiones preliminares de este artículo, sin los cuales no podría haberse concluido provechosamente.

1 "Manda en campaña papá... incómodo", Reforma, 13 de abril de 2015, en http:/ / ntrzacatecas.com/2015/04/13/manda-en-campana-papa-incomodo/

${ }^{2}$ Grabación "Papá de Aristóteles invita a cometer actos ilícitos durante las elecciones", 13 de abril de 2015, en https://www.youtube.com/watch?v=gl_FwpnPgEs, consultado el 22.VI.2015. 
recursos jurídicos para obtener la dimisión del magistrado. Su hijo interviene bajo la presión de los actores políticos locales y nacionales y le exige solicitar una licencia para abandonar temporalmente su cargo, lo cual hará unos días después. El magistrado con licencia retoma finalmente su puesto el 1 de mayo de 2015.

Este conflicto político local de envergadura nacional lleva a cuestionar el discurso acerca del avance democrático sostenido por los gobiernos mexicanos desde hace aproximadamente veinte años, de la misma manera que interroga los distintos usos y hechos de la observación electoral. En principio, un observador electoral no puede mantener ningún lazo directo con ningún partido y tiene un deber de reserva. La observación electoral es en su origen una práctica que busca contribuir a la democratización de un país. Esta práctica se desarrolla de manera floreciente en México y en muchos otros países. En este país, siete asociaciones crean en 1994 el movimiento "Alianza Cívica" (AC) con el propósito de vigilar la elección de ese año en el país, mediante la acción conjunta de diversos grupos locales de observadores electorales. Con el paso del tiempo, AC se establece como una asociación de dimensión contestataria de defensa de los derechos políticos y electorales, en cuyo seno el control de las elecciones supone vigilar también las instituciones públicas, durante y después del periodo electoral. En este artículo, se busca reconstituir el repertorio de acciones construido por AC para contestar las condiciones en las cuales se lleva a cabo la competencia política en este país. Con ello, pretendemos contribuir a la sociología de la observación electoral, que considera esta práctica como una forma de militancia "cívica" que se caracteriza por reivindicar su "independencia" frente a los partidos políticos y a los intereses constituidos y por contribuir al

${ }^{3}$ Véanse los estudios de R. Pozas, "La observación electoral: una modalidad de la militancia ciudadana”, Revista Mexicana de Sociología, vol. 59, núm. 2, 1997, pp. 23-40; S. Aguayo, "Electoral Observation and Democracy in Mexico", en Kevin Middlebrook (dir.), Electoral observation and democratic transitions in Latin America, San Diego, Center for U.S.-Mexican Studies, University of California, 1998, pp. 167-186; y J. M. Ramírez, "Movimientos ciudadanos y democracia: el caso de Alianza Cívica”, en J. Alonso y J. M. Ramírez (dirs.), La democracia de los de abajo en México, México, La Jornada-CIIH, 1997, pp. 29-52. 
involucramiento de los ciudadanos en la vida pública ${ }^{4}$ y a la democratización de los estados. ${ }^{5}$

Los estudios acerca de las ongs y asociaciones que hicieron observación electoral en América Latina en los años noventa han proporcionado, sin duda, un mejor conocimiento acerca de esta práctica. Sin embargo, sus reflexiones se centran esencialmente en el entendimiento del desarrollo y los efectos de la observación electoral en la vida política de países con gobiernos autoritarios. Ignoran con ello una vasta bibliografía, por lo general del área de relaciones internacionales, que aportó explicaciones interesantes sobre las relaciones entre observadores nacionales e internacionales ${ }^{6}$ y sobre la construcción de esta práctica como una norma internacional que pretende garantizar la celebración de elecciones en condiciones "free and fair".

Ahora bien, si esta bibliografía confirma el desarrollo, cada vez mayor desde la década de 1990, de las misiones de observación internacionales y de las ongs dedicadas a observar las elecciones en el país, muestra sobre todo cómo los actores internacionales buscan posicionarse como intermediarios en la resolución de conflictos electorales y políticos nacionales mediante esta práctica. Además, estos trabajos subrayan el establecimiento de un proceso

${ }^{4}$ Véanse N. Nevitte y S. Canton, "The Role of Domestics Observers", Journal of Democracy, vol. 8, núm. 3, 1997, pp. 47-61, y G. Flores, Para una pedagogía de la educación ciudadana, tesis, México, Universidad Intercontinental, 1998.

${ }^{5}$ Véanse T. Carothers, "The Observers Observed”, Journal of Democracy, vol. 8, núm. 3, 1997, pp. 17-31; y los trabajos de A. Olvera, Movimientos sociales prodemocráticos, democratización y esfera pública en México: el caso de Alianza Cívica, Veracruz, Universidad, 2001, y "Movimientos sociales prodemocráticos, democratización y esfera pública en México: el caso de Alianza Cívica”, en A. Olvera (coord.), Sociedad civil, esfera pública y democratización en América Latina: México, México, Universidad Veracruzana-Fondo de Cultura Económica, 2003, pp. 351-409.

${ }^{6}$ Cf. Carothers, art. cit., y S. Hyde, The pseudo-democrat's dilemma why election observation became an international norm, Londres, Cornell University Press, 2011.

${ }^{7}$ Véanse A. Santa-Cruz, "Monitoring Elections, Redefining Sovereignty: The 2000 Peruvian Electoral Process as an International Event”, Journal of Latin American Studies, vol. 37, núm. 4, 2005, pp. 739-767; Hyde, op. cit.; J. Elklit y P. Svensson, "What makes elections free and fair?", Journal of Democracy, vol. 8, núm. 3, 1997, pp. 32-46; e Y. Beigbeder, International monitoring of plebiscites, referenda and national elections self-determination and transition to democracy, Dordrecht, Nijhoff, 1994. 
de exportación del saber-hacer producido en el espacio de la asistencia electoral internacional, en el cual la observación de los escrutinios no es más que otro instrumento de la gran caja de herramientas destinada a promover la democracia. Finalmente, estos trabajos sugieren una adaptación de las prácticas internacionales de observación electoral por parte de los actores locales, ${ }^{8}$ evidenciando las tensiones entre el Estado y los actores contestatarios, sin que esta problemática sea forzosamente incluida en los análisis. El estudio de los actores que observan las elecciones a la luz de los trabajos sobre la utilización política del derecho en las acciones colectivas permitiría comprender mejor estas tensiones. Esos análisis, desarrollados considerablemente en Estados Unidos y en Francia, permiten identificar y cuestionar los procesos de juridización de las acciones colectivas y demuestran cómo los actores recurren al derecho para enfrentar abiertamente al Estado y obtener, al mismo tiempo, el reconocimiento de su acción. ${ }^{9}$ La integración del derecho en su repertorio de acciones se analiza como una estrategia, principalmente en el caso de los contextos autoritarios, pero también como un recurso, facilitando la exportación internacional del modelo de los derechos del hombre y de sus promotores. ${ }^{10}$

El movimiento de AC ofrece la posibilidad de analizar las estrategias adoptadas por los actores al margen de la competencia política para realizar la observación electoral y combatir con ello maniobras electorales y políticas de los gobernantes. Asimismo, sería posible con este análisis entender las tensiones entre actores nacionales e internacionales a una escala global. Este artículo pretende dar cuenta de las estrategias de acción adoptadas por AC e

${ }^{8}$ D. Donno (Defending Democratic Norms, Oxford, University Press, 2013) afirma que es importante distinguir "supervisión y aplicación". La supervisión es una forma de recopilar información sobre los comportamientos desviados, mientras que la aplicación supone sancionar ese tipo de comportamientos.

${ }^{9}$ Véanse "La justice comme espace politique. Trois études de cas: Israël, Inde, Argentine”, Droit et société, vol. 3, núm. 55, 2003; B. Gaïti y L. Israël, "Sur l'engagement du droit dans la construction des causes”, Politix, vol. 16, núm. 62, 2003, pp. 17-30; y L. Israël, L'arme du droit, París, Presses de Sciences Po, 2009.

${ }^{10}$ Consúltese Y. Dézalay y B. Garth, La mondialisation des guerres de palais, París, Seuil, 2002, y N. Guilhot, The Democracy Makers, Columbia, UniversityPress, 2005. 
identificar los ajustes de los recursos y del saber-hacer realizados por esta asociación, así como la manera en la que los militantes los utilizan. En otros términos, se trata de reconstituir el "repertorio táctico" 11 de este movimiento. Aún más, se busca discutir tanto la diversificación del sentido de la observación electoral como las transformaciones en la manera de apropiarse y utilizar el control electoral como un mecanismo para impugnar la autoridad política. Para hacerlo, en primer lugar, se presenta AC y el espacio nacional e internacional de la observación electoral desde los años noventa. En seguida, se analizan las transformaciones del repertorio de acciones de AC, que la llevan a interesarse tanto en el control electoral, como en el tema de la responsabilidad política. Finalmente, se cuestiona el recurso al derecho como una alternativa para legitimar la acción de esta asociación con respecto de las prácticas de los gobernantes. Concluiremos este artículo con una reflexión acerca de los efectos de la institucionalización de la observación electoral en la vida política mexicana. El enfoque adoptado en este análisis es el sociohistórico, que se apoya en diferentes tipos de materiales (véase apéndice).

El ESPACiO DE LA OBSERVACióN ELECTORAL

\section{El derecho a observar una elección}

Fundada el 25 de abril de 1994, AC se erige como heredera de las experiencias locales de vigilancia de las elecciones de los actores al margen de la competencia política de finales de la década de $1980 .{ }^{12}$ Tales experiencias se desarrollan principalmente en el norte del

${ }^{11}$ En torno a las evoluciones del concepto de "repertorio" de Charles Tilly y al interés en retomar el análisis de los repertorios sobre el evento y el tiempo, véase O. Fillieule, "Tombeau pour Charles Tilly Répertoires, performances et stratégies d'action”, en Éric Agrikoliansky, Isabelle Sommier y Olivier Fillieule (dirs.), Penser les mouvements sociaux, París, La Découverte, 2010, pp. 77-99.

12 Véanse R. Quintana, Movimientos populares en Chihuahua, Ciudad Juárez, Universidad Autónoma de Ciudad Juárez, 1991, p. 91, y A. Aziz, "Chihuahua y los límites de la democracia electoral”, Revista Mexicana de Sociología, vol. 49, núm. 4, 1987, pp. 178-179, 197. 
país y son constituidas por empresarios -los cuales cuentan con una importante presencia en la región y a quienes afectó la nacionalización de la banca en 1982-, una parte de la Iglesia católica y el Partido Acción Nacional (PAN) -único partido nacional de oposición en ese momento-, así como representantes de la clase media, considerablemente desarrollada y concentrada en las zonas urbanas desde la década de $1940 .{ }^{13}$ Estas acciones se inscriben en las acciones contra el régimen autoritario priísta, caracterizado por la constitución de un partido-Estado, en el cual hay una gran concentración de poder en manos del presidente. ${ }^{14}$ Desde los años sesenta, varios sectores de la sociedad se movilizan (estudiantes, médicos, guerrilleros, etc.) para expresar su descontento contra un régimen caracterizado por la falta de competencia política, un ejercicio desmesurado del poder, la violencia política y el control mediático. En realidad estas movilizaciones marcan el inicio del largo proceso de democratización del régimen político mexicano de finales del siglo xx, durante el cual las cuestiones electorales tienen un papel central. Las reformas electorales puestas en marcha durante los años setenta se preocupan por "canalizar el descontento de la oposición en las calles al ámbito electoral" 15 y facilitar con esto el acceso de la oposición al espacio político. Uno de los principales beneficios de estas reformas es el establecimiento de las bases para la construcción de un cierto pluralismo político, así como el inicio del proceso de reforma de las instituciones públicas según los principios de autonomía y transparencia. Se debe en parte a estos cambios que hoy se tenga a México por un país "democrático". Sin embargo, es necesario señalar que el pluralismo político sigue siendo limitado y que la forma de gobierno continúa estando marcada

${ }^{13} \mathrm{Al}$ respecto, consúltese L. Barraza e I. Bizberg, "El Partido Acción Nacional y el régimen político mexicano”, Foro Internacional, vol. 31, núm. 3, 1991, pp. 418445; y de S. Loaeza, "El papel político de las clases medias en el México contemporáneo”, Revista Mexicana de Sociología, vol. 45, núm. 2, 1983, pp. 407-439, y Clases medias y política en México. La querella escolar, 1959-1963, México, El Colegio de México, 1988.

${ }^{14}$ Véase Barraza y Bizberg, art. cit.

15 R. Y. Ortega Ortiz, Movilización y democracia: España y México, México, El Colegio de México, 2008, p. 206. 
por la corrupción y las violaciones al estado de derecho de los mexicanos. El sistema político mexicano mantiene con vida antiguas prácticas autoritarias que coexisten hoy en día con prácticas propias de un gobierno democrático, razón por la cual varios especialistas concuerdan al definir el sistema político mexicano utilizando términos a priori contradictorios: "democracia autoritaria", ${ }^{16}$ "dictablanda" o "democradura". ${ }^{17}$

Con las elecciones de 1988 se dio un giro en la historia electoral mexicana. A partir de esta época, las acciones de contestación de los resultados electorales se multiplicaron e intensificaron: entre 1989 y 1994, 15 de los 31 estados presentan movilizaciones postelectorales de gran magnitud y se desarrollan manifestaciones espontáneas contra los resultados en casi todos los estados. ${ }^{18}$ Esta época estuvo también marcada por el acceso de la oposición a diferentes puestos de representación política, hasta entonces monopolizados por el PRI. La oposición, que está relativamente bien implantada en los municipios, gana por primera vez desde 1928 seis elecciones para gobernador. ${ }^{19}$ En estas circunstancias, se forma una campaña en defensa del voto que reúne actores de orígenes políticos distintos: el Partido de la Revolución Democrática (PRD), una parte de la Iglesia, el PAN, algunos patrones y un "movimiento cívico" que se distingue por reivindicar su independencia ante los partidos políticos. Esta campaña consiste sobre todo en llevar a cabo acciones que evidencien las maniobras electorales del PRI para obtener el control político del país, gracias a las cuales logra mantener el control del gobierno durante 71 años y regresar a éste en 2012. En sus inicios, la observación electoral se hace de manera informal, exponiendo a aquellos que la realizan a una represión violenta. Los partidos políticos se apoyan en sus representantes de

${ }^{16}$ L. Meyer, Nuestra tragedia persistente. La democracia autoritaria en México, México, Debate, 2013.

${ }^{17}$ S. Marti I Puig, R. Y. Ortega Ortiz y M. F. Somuano Ventura, La democracia en México. Un análisis a 10 años de la alternancia, Barcelona, Bellaterra, 2011.

18 Véase $\mathrm{H}$. Combes, De la politique contestataire à la fabrique partisane, tesis, $\mathrm{Pa}-$ rís, Université Paris 3, 2004.

19 Entre 1989 y 1995, seis candidatos de oposición ganaron la elección al puesto de gobernador. Véase R. Pozas, art. cit., p. 27. 
casillas para vigilar las elecciones, mientras que los actores del movimiento cívico deben, por su parte, hacerse pasar por representantes de partido o recurrir a otros medios.

En 1994, el espacio de la observación electoral cambia considerablemente. Vigilar las elecciones se convierte en asunto de partidos políticos, organizaciones y asociaciones (nacionales e internacionales), gracias a la adopción de las figuras de "observador electoral" y "visitante extranjero". Esta transformación se explica en gran medida por el tenso contexto político y social en el cual se encuentra el país, a causa de la declaración del Ejército Zapatista de Liberación Nacional (EZLN) el 1 de enero de 1994. Aunque este movimiento parezca circunscrito a un nivel local, defiende en realidad una causa legítima ante los ojos de toda la sociedad: la defensa de los derechos de las comunidades indígenas. Además, la crisis política que atraviesa el país no tiene precedente; la violencia política toca a una de las figuras más emblemáticas del momento: el candidato del PRI a la presidencia de la República, Luis Donaldo Colosio, es asesinado de manera violenta durante un mitin de campaña. Estos hechos ocurren al mismo tiempo que culminan las negociaciones del Tratado de Libre Comercio de América del Norte (TLCAN $)^{20}$ y que la configuración del espacio político cambia volviéndose cada vez más diverso y competitivo: nueve partidos políticos obtienen su registro nacional para la elección de 1994.

En el mundo, el conjunto de sucesos violentos y el clima contestatario llevan a cuestionar los avances en lo que atañe a los derechos humanos y a la democracia en este país, sobre todo por parte de Estados Unidos. Para restablecer la imagen internacional de México, ${ }^{21}$ el gobierno de Carlos Salinas de Gortari decide invitar a algunos observadores internacionales a vigilar la elección en curso. El régimen autoritario, que históricamente mantiene una

${ }^{20}$ Con este tratado se creó una zona de libre comercio entre México, Canadá y Estados Unidos que elimina sobre todo las barreras arancelarias y facilita los intercambios transfronterizos de bienes y servicios. Las exportaciones mexicanas a Estados Unidos en 2012, por ejemplo, representaron el $78 \%$ del total de sus exportaciones.

${ }^{21}$ Véase A. Covarrubias, "El problema de los derechos humanos y los cambios en la política exterior”, Foro Internacional, vol. 39, núm. 4, 1999, pp. 429-452. 
política extranjera de no intervención, ${ }^{22}$ limita la participación de los observadores, aclarando que se trata de una "invitación". La presencia de los observadores internacionales nunca se vislumbró como una presencia extranjera de facto, donde el Estado tenga un papel menor. ${ }^{23}$ Con todo, este mismo año el gobierno reconoce el papel del "visitante extranjero" en el caso de los actores internacionales y el de "observador electoral" en el de los nacionales. Esta decisión se acompaña del establecimiento de un "Fondo de apoyo a la observación electoral" para financiar las acciones de observación de los actores nacionales. ${ }^{24}$ Éste, de varios millones de dólares, es renovable cada elección federal y representa un hecho inédito en América Latina. Más allá de las fronteras mexicanas, diferentes misiones internacionales de observación y una nueva generación de asociaciones de derechos humanos, financiadas en parte por fundaciones humanitarias y organismos internacionales, empiezan a ocupar también el ámbito de la observación electoral.

AC nace en estas circunstancias. Fundada por iniciativa de siete organizaciones del "movimiento cívico", reúne una gran variedad de actores: asociaciones, agrupaciones políticas más o menos establecidas (nacionales o locales), universitarios, militantes de partidos de oposición de izquierda o de derecha, grupos religiosos, líderes sindicales, periodistas y ciudadanos en general. Se define como un movimiento "plural e incluyente", cuyo objetivo es "apelar, federar y coordinar la participación ciudadana para apoyar la construcción de la democracia”. ${ }^{25}$ Respecto a su predecesor, el Movimiento Ciudadano, para AC la observación es un medio que garantiza la "correcta" celebración de las elecciones, es decir en el respeto a las reglas vigentes en un régimen democrático. AC se organiza en torno a una oficina central y a "Alianzas locales", cuyo número varía sensiblemente según el año. Como punto de

${ }^{22}$ Cf. J. Treviño Rangel, "Las ONG de derechos humanos y la redefinición de la soberanía del Estado Mexicano”, Foro Internacional, vol. 44, núm. 3, 2004, pp. 509-539.

${ }^{23}$ Covarrubias, art. cit.

${ }^{24}$ IFE, "Fondo de apoyo para la observación electoral", sin fecha.

${ }^{25}$ Archivos de la Alianza Cívica (AAC en las notas siguientes), Boletín, núm. 1, mayo-junio, 1996. 
referencia, se podría decir que sus militantes activos oscilan entre 30 y 120 y solamente algunos cuantos son asalariados (oficina central). Este movimiento se construye bajo la idea de realizar tres objetivos: "observar las elecciones", "vigilar la función pública" y "reforzar a la sociedad civil con la implementación de consultas nacionales y referendos". ${ }^{26}$ Para hacerlo, se busca hacer públicas las irregularidades del proceso electoral, promover la responsabilidad política y apoyar la intervención de los ciudadanos en la vida pública. Durante la elección de 1994, AC representó y coordinó 11800 observadores electorales, es decir el 14.45\% del total de los observadores participantes. Desde entonces, el movimiento se debilita considerablemente; en 2012, presentó solamente 500 observadores, el $1.52 \%$ del total de observadores electorales de ese año.

\section{Actuar por unas elecciones "free and fair"}

Si la presencia de los observadores electorales internacionales en México representa un cambio mayor en lo que toca a la política exterior, esto se inscribe también en el marco del movimiento internacional que defiende el derecho a un gobierno democrático y el principio de elecciones "free and fair". ${ }^{27}$ Este principio, que ha promovido Naciones Unidas desde los años setenta, busca establecer un conjunto de criterios que permita definir los comportamientos legítimos e ilegítimos durante una elección. Históricamente la Organización de Estados Americanos (oEA) y la Organización de Naciones Unidas (ONU) han enviado misiones internacionales de observación y ayuda a varios países en la organización de sus elecciones.

En América Latina, es la oeA la que mantiene una fuerte presencia en materia de observación electoral. Entre 1962 y 1989 envió

${ }^{26}$ Idem.

${ }^{27} \mathrm{El}$ concepto se usó por primera vez en 1956 en el informe de Naciones Unidas sobre el referendo de la independencia de Togo. Cf. Beigbeder, op. cit., y Elklit y Svensson, art. cit., pp. 32-46. 
15 misiones, ninguna a México. ${ }^{28}$ Este país rechazó sistemáticamente este tipo de acciones bajo el argumento de los riesgos que representarían a su soberanía. Cabe señalar que por entonces se acusaba a la oeA de servir a los intereses estadounidenses. ${ }^{29}$ Sin embargo, la observación de las elecciones en Nicaragua, en 1990, en el marco del proceso de pacificación de América Central (el Acuerdo de Esquipulas II), representa un giro en la observación internacional de las elecciones. Para tener un papel más activo en el mundo, la OEA, la onU (presente por primera vez en la región), el Centro Carter y el Centro para la Democracia (ambas ongs internacionales), trabajan juntos y desarrollan un modelo de observación llamado "observación integral". ${ }^{30}$ Se trata de fortalecer, con precisión, su papel de agentes legitimadores de las elecciones y forjarse un lugar como mediadoras en los conflictos políticos nacionales. Esta forma de intervención obtiene cierto éxito en el contexto de contestación de los gobiernos autoritarios. Entre 1990 y 1994, la oeA envía diez misiones de observación a países como Haití, El Salvador, Perú, Paraguay, República Dominicana y Panamá, ${ }^{31}$ con lo cual confirma su presencia en la región.

Hasta ese momento, México parece estar aislado de ese movimiento. Sin embargo, durante esa época se cabildea con partidos políticos y asociaciones civiles para convencerlos de apoyar la presencia de los observadores internacionales en ese país. El Centro Carter desempeña un papel principal. Por conducto de uno de sus colaboradores, cercano al presidente mexicano de ese entonces, el cual dispone de un amplio capital de relaciones sociales en el

${ }^{28}$ Véase J. McCoy, "Monitoring and Mediating Elections during Latin American Democratization”, en K. Middlebrook (dir.), Electoral observation and democratic transitions in Latin America, San Diego, Center for U.S.-Mexican Studies, University of California, 1998, p. 57.

29 Véase A. Santa-Cruz, Mexico-United States Relations, Londres-Nueva York, Routledge, 2012.

${ }^{30}$ Se trata de observar lo que pasa tanto durante la campaña electoral como durante las jornadas electorales, así como de emitir reportes periódicos sobre el estado de las reglas electorales, las condiciones de la campaña y el desarrollo de los procesos electorales.

${ }^{31}$ Cf. McCoy, art. cit., pp. 59-60. 
sector académico y en el espacio político y asociativo, se plantea una estrategia para que militantes de partidos y asociaciones participen en la observación de la elección presidencial en Estados Unidos y/o en algún otro país latinoamericano (Haití y Panamá). Los militantes de las asociaciones del movimiento cívico apoyan la propuesta, mientras que los partidos políticos muestran poco interés. La estrategia rinde sus frutos con bastante rapidez. Por iniciativa de ocho grupos de observadores electorales, Sergio Aguayo, que participó en dos misiones de observación organizadas por el Centro Carter y más tarde será uno de los fundadores de AC, invita al Centro a observar las elecciones de Chihuahua y Michoacán en 1992. La invitación se hace a pesar de que la presencia de los observadores internacionales estuviera oficialmente prohibida. Al aceptar, el Centro Carter dirige un fuerte mensaje al gobierno mexicano.

La observación internacional se vuelve una apuesta mayor. Es por ello que el gobierno mexicano solicita por primera vez en 1994 la instalación de una misión de asistencia electoral a la onU, quien asume su papel habitual de consejero y gestiona además el Fondo de apoyo a la observación electoral mediante su representación mexicana del Programa de Naciones Unidas para el Desarrollo (PNUD). Su intervención se limita finalmente a dar apoyo a los grupos de observación nacionales y realizar una evaluación global del sistema electoral mexicano. México representa un reto para Naciones Unidas, tan sólo por el tamaño del país y el número de casillas electorales. Para la elección de 1994 se requirieron 96 393, mientras que en El Salvador, en 2015, se instalaron 1599 en todo el país.

Durante esta elección, AC es la primera y única asociación civil que dispone de los medios necesarios para realizar una observación en el país: reúne a más de 300 grupos nacionales y locales, cuenta con experiencia en materia de observación y es reconocida entre los actores internacionales. Se vislumbra, en algún punto, la posibilidad de conferirle todo el financiamiento del Fondo. Sin embargo, rápidamente una decena de asociaciones se constituyen y consiguen reunir las condiciones para poder ser beneficiadas por los fondos. Las relaciones entre AC y el PNUD se tensan a tal punto que este último limita su intervención a un apoyo exclusivamente financiero, viendo cuestionada su legitimidad de consejero técnico en 
materia electoral. Las divergencias entre ambas organizaciones se deben a la metodología de observación que pretende usar Ac. Para el PNUD se trata de una confusión relacionada con los dos papeles que le toca desempeñar en esta ocasión: por un lado, ser el responsable de la gestión de los recursos y, por otro, ser el consejero técnico. ${ }^{32}$ Según AC, los especialistas del PNUd no comprendían la particularidad de la situación mexicana. En las palabras de Sergio Aguayo, responsable de las relaciones entre el PNUD y AC, esas elecciones eran "un momento histórico [...] para el cual nos hemos preparado durante años, [...] sabemos más que ustedes [el PNUD] sobre lo que pasa en México, y cómo se hacen las irregularidades en México". 33

Dado el complejo contexto político y económico que aumenta el interés por la observación electoral, la extensión de su red y los lazos de ciertos militantes con las altas esferas políticas, AC logra defender su proyecto y su manera de actuar ante el PNUD, colocando a este último en una situación delicada a causa de la extensión de su papel habitual de consejero a "gestor de recursos". Las relaciones del PNUD con los actores nacionales y su reconocimiento como agente legitimador de las elecciones se ven disminuidos.

Las tensiones entre el PNUD y AC dejan entrever las sutilezas del control electoral, así como los conflictos en razón de los intereses y posiciones distintas de cada uno de los actores. El PNUD busca consolidar su papel de agente legitimador de las elecciones a pesar de las numerosas críticas a su modelo de observación. ${ }^{34}$ Para AC, observar es un medio para luchar contra la normalización de las prácticas de manipulación electoral y política en la era de los gobiernos priístas. Esforzarse por establecer un lazo entre su acción y el discurso democrático internacional, inscribiéndose en el "mercado de las actividades de asistencia internacional, en particular en el ámbito electoral (observación, ingeniería institucional, asistencia

${ }^{32}$ Entrevista del 14 de marzo de 2008 con uno de los responsables de la primera misión del PNUD en México (hombre de 62 años y funcionario de dicha institución).

${ }^{33}$ Entrevista del 12 de marzo de 2008 con Sergio Aguayo Quezada, fundador de la Ac.

${ }^{34}$ Véanse Elklit y Svensson, art.cit., pp. 32-46, y Hyde, op. cit. 
técnica, etc.)", ${ }^{35}$ es una de las estrategias utilizadas por Ac para sostener su causa y lograr establecerse permanentemente en el espacio político mexicano.

\section{IMPONERSE COMO GARANTE DE LAS INSTITUCIONES MEDIANTE UN SABER-HACER INSTITUCIONAL}

A la inversa de otros países de América Latina, en México las elecciones se celebran periódicamente desde 1928. Sin embargo, éstas han contribuido a legitimar la fachada democrática construida por los gobiernos priístas. Aunque el control electoral sea en 1994 un medio empleado por el gobierno para restablecer la confianza quebrantada en las instituciones, con ello se contribuye a generar un debate acerca de la manipulación de las instituciones y las maniobras políticas y electorales ejercidas históricamente por el partido-Estado. El fraude electoral se vuelve un tema central en la vida política de este país. Como lo afirma Fabrice Lehoucq, el "fraude electoral" tiene un carácter normativo que penetra en el discurso de los movimientos "democráticos" y los lleva a formular sus reivindicaciones en términos de violación de principios y libertades democráticos liberales. ${ }^{36}$

En realidad, Ac enarbola una lucha por la defensa de los derechos políticos y electorales que trasciende los procedimientos electorales. Su propósito es "establecer mecanismos y espacios institucionales y jurídicos que consoliden la democracia y que promuevan una nueva cultura ciudadana anclada en los valores democráticos". ${ }^{37}$ Tres tipos de actividades parecen necesarias: recopilar datos para legitimar las reivindicaciones, crear mecanismos

35 N. Huu Dong y D. Recondo, "L'onu, artisan du processus électoral”, Critique internationale, núm. 24, 2004, p. 169.

36 "Electoral Fraude: Causes, Types, and Consequences", Annual Review of Political Science, núm. 6, pp. 233-256. A propósito del fraude electoral, véase también N. Dompnier, La clef des urnes, tesis, IEP de Grenoble, 2002; A. Garrigou, Histoire sociale du suffrage universel en France 1848-2000, París, Seuil, 2002; e Y. Déloye y O. Ihl, L'acte de vote, París, Presses de Sciences Po, 2008.

${ }^{37}$ AAC, boletín citado, p. 1 . 
que inciten a los ciudadanos a involucrarse en los asuntos públicos y elaborar instrumentos para supervisar el ejercicio de poder de los gobernantes.

Para afrontar la política represiva y la violencia con la cual se contenía hasta entonces a los actores críticos del sistema, AC funda su acción en la producción de pruebas y actividades que puedan ser sustentadas con la legitimidad del derecho. ${ }^{38}$ Actuando de esta manera, busca distinguirse de otros actores que observan también las elecciones. Entre los miembros de AC, se encuentran sobre todo personas que cuentan con educación superior, provenientes de sectores profesionales como la enseñanza y la investigación, el periodismo y el sector asociativo, que tienen además una experiencia militante. Su composición social explica en parte por qué logra desarrollar un repertorio de acciones que se caracteriza por su alto grado de especialización.

\section{Observar para contestar}

Con la apertura de la observación electoral a los actores que no participan en la competencia política, AC elabora un repertorio de acciones basado en el principio de la honestidad del escrutinio. ${ }^{39}$ Observar una elección es una acción que permite reunir pruebas que demuestren si la elección se realizó bajo el respeto de las reglas electorales, es decir conjuntar los elementos que comprueben la existencia o no de prácticas electorales fraudulentas. En su informe sobre la observación de las elecciones de 1994, Alianza apunta a las maniobras empleadas por el PRI para evitar que los votantes ejercieran su derecho de voto libremente. Se concluye, por ejemplo, que "el Partido de Estado es quien crea, reproduce y lleva a cabo la compra y coacción del voto". ${ }^{40} \mathrm{El}$ fraude electoral, como apunta

${ }^{38}$ Consúltese E. P. Stevens, "Legality and Extra-Legality in Mexico", Journal of Interamerican Studies and World Affairs, vol. 12, núm. 1, 1970, pp. 62-75.

${ }^{39}$ Sobre la cuestión de la sinceridad electoral, véase Déloye e Ihl, op. cit., y Dompnier, op. cit.

${ }^{40}$ AAC, "Informe final del campo de observación, compra y coacción del voto”, Alianza Cívica/Observación 94, sin fecha, p. 6. 
Nathalie Dompnier, "es antes que nada una construcción política y social, fruto de una actividad social de definición y de categorización". ${ }^{41}$ En México, este trabajo de definición y de categorización se hace más evidente durante la década de 1980, con el incremento considerable de movimientos y actores que cuestionan los resultados electorales. Éstos se organizan principalmente en partidos políticos, asociaciones y otros sectores de la sociedad, como la iglesia y algunos patrones. AC contribuye así a la categorización del fraude electoral con su trabajo de identificación de las prácticas electorales que se sitúan al margen de la norma, sobre todo a partir de la observación electoral. Concretamente, AC realiza tres tipos de actividades: el control del financiamiento atribuido a los partidos políticos y la mediatización de los candidatos, la vigilancia del desarrollo de la jornada electoral y la comunicación de los resultados electorales al final de la jornada (véase cuadro 1). Tales actividades cubren en realidad las fases del modelo de "observación integral" defendido en el mundo. Sin embargo, AC realiza un conteo rápido con el propósito de hacer públicas las tendencias del resultado del voto al final de la jornada. Un aspecto extremadamente sensible en el contexto de cambio de régimen.

Los observadores electorales son un elemento fundamental para el movimiento. No sólo porque representan su base y son los responsables de la ejecución de las acciones en el terreno, sino también porque la información obtenida a partir de las acciones de observación permite identificar otras problemáticas que a su vez posibiliten formular nuevas reivindicaciones. Fue así, por ejemplo, que hace suya la lucha por la revisión de las reglas de atribución del financiamiento público a los partidos políticos para las campañas: “YYa basta! ¡Menos dinero para los partidos políticos!” El trabajo como observador implica una inversión de tiempo considerable (participar en las actividades previas a la jornada electoral, formarse y permanecer en la casilla electoral durante toda la jornada) y adquirir conocimientos relativamente especializados sobre las elecciones. Además, su participación puede resultar riesgosa en el caso

${ }^{41}$ Op. cit., p. 42. 
de lugares en los cuales el acceso es complicado, a pesar de la ayuda brindada por las comunidades eclesiásticas de base en estas regiones $^{42}$ (véase cuadro 2). En las palabras de Carlos Peralta, antiguo responsable de AC en Jalisco: "los misioneros se encargaron de la observación en municipios muy remotos de aquí del estado de Jalisco, partes indígenas y otras; los Javerianos se encargaron de otras partes también poco accesibles". ${ }^{43}$

\title{
Cuadro 1 \\ La observación electoral en AC
}

\begin{abstract}
Observación Su propósito es establecer las preferencias de los ciudadanos por de la campaña un candidato o un partido político, así como obtener información sobre los debates acerca de la elección en curso y las manifestaciones militantes. Por un lado, tres meses antes de la elección, AC inicia un conteo por muestreo de las menciones hechas en los medios (periódicos y televisión) de cada candidato y del proceso electoral (promoción del voto y reglas electorales). ${ }^{\text {a }}$ Por otro, recopila datos sobre la organización de las campañas electorales y el desempeño de los candidatos y militantes a partir de entrevistas y cuestionarios requisitados por los militantes (número de participantes, tipo de manifestación organizada, lugar, si los partidos políticos dan o no regalos a los ciudadanos, etc.). ${ }^{\mathrm{b}}$
\end{abstract}

Observación Los observadores electorales representan a AC el día de la votación. de la jornada Son responsables del conteo rápido y de las encuestas sobre las conelectoral diciones de voto y de reunir información acerca de las condiciones en las cuales el ciudadano emite su voto, observando lo acontecido durante la instalación y apertura de las casillas, el comportamiento de los funcionarios electorales y los representantes de los partidos políticos, así como las violaciones a las reglas electorales. Deben comunicar por teléfono sus observaciones dos veces al día: a las 11:00 a.m. y al final de la jornada, siguiendo un formato creado para tal efecto. Además, deben transmitir los resultados de su casilla para que sea posible efectuar el conteo rápido. ${ }^{c}$

42 Varios responsables de las Alianzas locales de Jalisco, Michoacán, San Luis Potosí y Aguascalientes, que conocimos durante nuestra investigación, sostienen lo anterior.

${ }^{43}$ Entrevista del 2 de marzo de 2006 con Carlos Peralta. 


\section{CuAdro 1 (concluye)}

Comunicación Los resultados de la observación de la campaña y la jornada electoral de los se comunican de diferentes maneras: por informes utilizados como resultados herramientas de comunicación después de las elecciones y del anunelectorales cio público de la tendencia de la votación al cierre de las casillas.

a Véanse los siguientes documentos del AAC: "Campos de la observación 5. Propuesta de análisis de contenido electoral de medios de comunicación”, 1994; "Informe especial sobre la observación integral de los procesos electorales de Guanajuato y Yucatán de 1995", sin fecha; "Informe de la observación previa a la jornada electoral y evaluación de las condiciones con que se llegan a las elecciones", 1996; y "Las elecciones en Yucatán. Informe preliminar de la observación electoral, Frente Cívico Familiar-mujeres yucatecas en lucha por la democracia-Grupo Indignación”, 1993.

b AAC, "Campos de la observación 2. Observación de campañas políticas", 1994, p. 2.

c AAC, "Guía de observación de la calidad de la jornada electoral", julio de 2006. Alianza Cívica A. C. Informe final”, 2009.

\section{Cuadro 2 \\ Los observadores electorales}

Como Delia, muchos observadores participan en AC de manera puntual. Maestra de secundaria, participó con AC en la observación de las elecciones de 1994, 1997 y 2000. Durante estas experiencias, conoció a otros observadores que eran estudiantes, pequeños empresarios, amas de casa, profesionistas (médicos, abogados, ingenieros, etc.), campesinos, empleados de pequeños comercios y asistentes sociales. Ante tal diversidad social, la formación es una fase importante cuyo objetivo es adquirir competencias en materia electoral. Los futuros observadores reciben una "pedagogía electoral" que consiste en transmitirles conocimientos electorales, presentarles escenarios considerados problemáticos (tensiones entre representantes de partido y funcionarios de casilla, violencia física, insultos, identificación de las inconsistencias) y familiarizarlos con los materiales electorales (documentos que deben requisitar los funcionarios de casilla, urnas, boletas de voto, etc.). Tanto la formación del IFE como la de AC se organizan en torno a cinco temas: la historia de los institutos electorales locales, las fases del proceso electoral, la jornada electoral, los derechos y obligaciones de los observadores electorales y los derechos y obligaciones de los representantes de los partidos políticos. ${ }^{\mathrm{a}}$

a IEPC, "Lineamientos para la observación electoral. Proceso electoral local. 2008-2009", sin fecha, p. 6, y entrevista con Delia Tena, antigua militante de la AC, el 22 de febrero de 2006, en Guadalajara. 
En 1994, AC fue la primera en publicar el resultado de la elección para presidente con base en un muestreo de 232 casillas que resultó muy cercano al resultado final. En esa época, el estudio de la opinión pública mediante sondeos y conteo rápido se encontraba en sus inicios en este país. Ser la primera en comunicar los resultados de la elección era un objetivo para AC, en la medida en que esto confirmaría la pertinencia de su metodología, fuertemente cuestionada por el PNUD. Al mismo tiempo, esto la posicionaría en una situación de competencia ante las agencias especializadas en estudios de opinión y de desafío frente al Instituto Federal Electoral (IFE), actual INE, responsable de la organización de las elecciones y único organismo habilitado para revelar las tendencias del voto al cierre de las casillas. Esa noche, AC confirma la victoria del candidato del PRI, lo cual suscita reacciones de desconfianza entre sus propios militantes. Aunque estas tensiones no hayan ocasionado una ruptura, la independencia del movimiento se cuestiona y las relaciones entre la oficina central y las alianzas locales se tensan. Motivados por el sentimiento de éxito tras la primera experiencia de observación, los militantes deciden establecer de forma definitiva AC en cuanto que "asociación cívica" durante su asamblea nacional del 30 de septiembre y 1 de octubre de 1994.

El informe de la observación de 1994 de AC muestra que la administración de la prueba se realiza sobre todo a partir de un análisis cualitativo y no cuantitativo. Por ejemplo, en éste se incluye una lista de 24 casos concretos de violación de reglas reportados por los observadores:

- En Paloma Armadillo de los Infantes San Luis Potosí, la maestra María Luisa Guerrero condicionó la entrega de despensas y becas para niños a cambio de votar por el PRI, lo cual se informó al diputado Gerardo Limón, quien no actuó al respecto, denuncia Guillermina Rodríguez.

- En Santa María de Guido, un pequeño poblado del área urbana de Morelia, Michoacán, obligaron a la gente a asistir al mitin de Zedillo, y a quienes no lo hicieron se negó la entrega de leche LICONSA. ${ }^{44}$

${ }^{44}$ Véase aAc, "Informe final del campo de observación...", pp. 3-4. 
En un país como México, donde las desigualdades sociales son tan graves y el gobierno ejerce históricamente una política social de tipo asistencialista, la compra de votos a cambio de ayuda o de dinero es más probable. A pesar de que cientos de casos de violación de las reglas electorales son documentados por Alianza durante la observación de diversas elecciones, nacionales o locales, ${ }^{45}$ su representatividad así como la transformación de las prácticas políticas y electorales fraudulentas son difíciles de comprobar, como lo confirma Nathalie Dompnier en su trabajo sobre la medición de los fraudes electorales. ${ }^{46}$ En realidad los informes de la observación de 1994 de AC son un medio para denunciar y documentar las violaciones de las reglas electorales y las fallas del sistema electoral. Orientando su trabajo por la idea de evidenciar la persistencia de las maniobras electorales, Alianza continúa luchando por la democracia, para contribuir a que persista la suspicacia de los ciudadanos para con las instituciones. Con ello, no se busca adoptar una posición únicamente contestataria, sino privilegiar la construcción de un espacio donde puedan reconocerse y reunirse diferentes posiciones políticas en torno al leitmotiv de la defensa del "derecho a un gobierno democrático". ${ }^{47}$ Permanecer activa fuera del contexto electoral y mantener el interés de sus miles de observadores es el reto que deberá afrontar Ac.

\section{Dar voz a los ciudadanos}

AC es la primera en organizar un dispositivo de participación directa a nivel nacional en este país. Ella cuenta con la experiencia de sus organizaciones fundadoras. La Fundación Rosenbleuth, por ejemplo, organizó en 1993 el referéndum sobre la reforma política del

${ }^{45}$ Por ejemplo, en un proyecto sobre las prácticas de coerción y de compra de votos, llegaron 1400 casos a la sede de Ac, provenientes de nueve estados, mientras que durante la observación de las elecciones de Chiapas en 1997, se registraron más de 300 casos y otros 180 en las del año 2000.

46 "La mesure des fraudes électorales. Difficultés méthodologiques et enjeux politiques”, Histoire Ė Mesure, vol. 22, núm. 1, 2007, pp. 123-144.

${ }^{47}$ Santa-Cruz, art. cit., p. 767. 
Distrito Federal, a solicitud del gobierno. ${ }^{48}$ Con la idea de que los ciudadanos expresen su posición acerca de los problemas económicos, sociales y políticos, Alianza crea diversos dispositivos: las primeras consultas ciudadanas, llevadas a cabo sobre todo en zonas urbanas, trataron la cuestión de la situación económica del país en el contexto de la entrada en vigor del TLCAN y de la crisis económica que, en 1995, hizo caer un $7 \%$ el PIB con respecto del año anterior. Otras consultas y referendos fueron igualmente realizados durante esta época sobre temas más políticos, como la paz en el sur del país a causa del levantamiento zapatista o la manera en la que debería consolidarse el proceso de democratización. Tales dispositivos se concibieron inspirándose en la metodología creada para la observación de los escrutinios (véase cuadro 3) y, aunque no susciten el mismo interés, conllevan la instalación de miles de módulos de consulta y movilizan cientos de miles de ciudadanos (véase cuadro 4).

\section{Cuadro 3 \\ Consultas ciudadanas y referendos}

Para participar se requiere comprobar la nacionalidad mexicana, tener más de 18 años de edad y una credencial de elector vigente. El material de comunicación y los cuestionarios se elaboran según los temas por tratar y se instalan "módulos de consulta” en los puntos más concurridos de las ciudades: plazas, mercados, iglesias, jardines públicos, cines. Tres militantes son responsables de los módulos y uno de ellos debe además ejercer el papel de "promotor" para atraer la atención de los transeúntes. El trabajo de comunicación durante este tipo de actividades es menos importante que el llevado a cabo durante la observación electoral. Es por esto que en el marco de estas actividades se otorga una mayor atención a la decoración de los módulos: se colocan globos de colores, grandes banderolas y carteles fabricados por los militantes. Además, los "módulos de consulta móviles" se desplazan durante toda la jornada de un lugar a otro para que los ciudadanos los vean. Los resultados de las consultas y referendos se comunican durante las conferencias de prensa e informes previstos para este efecto. ${ }^{a}$

a AAC, "Consulta ciudadana del 26 de febrero. Informe final", sin fecha, pp. 1-2; AAC, “Asamblea Nacional”, 14 de diciembre de 1996, pp. 8-10.

${ }^{48}$ La participación es importante: 330000 individuos respondieron tres preguntas. Cf. AAC, "20 plebiscito ciudadano sobre la reforma política del Distrito Federal", 1993. 


\section{Cuadro 4}

Participación en las consultas ciudadanas y referendos

\begin{tabular}{|c|c|c|c|c|}
\hline Año & & Número de & Número de & Tasa de \\
\hline 1995 & $\begin{array}{l}\text { Consulta nacional por la paz y la } \\
\text { democracia }\end{array}$ & 3591 & 1088094 & $2.37 \% *$ \\
\hline 1996 & Consulta nacional ciudadana & $\mathrm{S} / \mathrm{d}$ & 660185 & $1.44 \% *$ \\
\hline 1996 & $\begin{array}{l}\text { Primera jornada nacional de } \\
\text { condena a la política económica } \\
\text { del gobierno }\end{array}$ & 8652 & 182386 & $0.39 \% *$ \\
\hline 1996 & Referéndum de la libertad & $\mathrm{S} / \mathrm{d}$ & 428195 & $0.93 \% *$ \\
\hline 2011 & $\begin{array}{l}\text { Consulta ciudadana del Estado } \\
\text { de México }\end{array}$ & 960 & 250985 & $0.31 \% * *$ \\
\hline
\end{tabular}

* Porcentaje calculado según el número de electores inscritos en el padrón electoral de 1994.

** Porcentaje calculado según el número de electores inscritos en el padrón electoral de 2006.

Fuente: la autora, a partir de diferentes fuentes.

Como muestra el cuadro, el nivel de participación en las consultas ciudadanas y en los referendos no es representativo, sobre todo cuando se compara con la tasa de participación de la elección presidencial precedente, que es del $77.16 \%$ en 1994 y del $58.55 \%$ en $2006 .{ }^{49} \mathrm{El}$ problema de la representatividad de las consultas se invoca frecuentemente en las conferencias de prensa. Se trata de un problema importante, puesto que se pretende recoger la opinión de "todos" los ciudadanos. En el informe de la consulta nacional de 1996, se precisa lo siguiente:

Una consulta ciudadana no es un ejercicio estadístico, no es una encuesta que busca ser representativa con muy pocos encuestados. Una consulta ciudadana es ante todo una movilización de la sociedad y es $100 \%$ representativa de todos los que participan en ella. Las características más importantes de las consultas es que están abiertas a todos

${ }^{49}$ La comparación toma sentido en la medida en que las condiciones de participación en las consultas son idénticas a las que rigen el derecho al voto. 
los ciudadanos y ciudadanas que quieran participar, cosa que desde luego no sucede con las encuestas que son selectivas, de manera que éstas no permiten que los ciudadanos expresen su opinión libremente como las consultas". ${ }^{50}$

Justificar el poco interés por estos dispositivos argumentando que éste no predetermina el derecho que cualquiera tiene a participar, sino que, por el contrario, permite la participación de "todos”, es un ejercicio retórico, ya que durante la observación de las elecciones, esta asociación reivindica con fuerza y determinación el tamaño de su red de observadores y la representatividad de las acciones de vigilancia de los medios y de los pronósticos electorales, con base en métodos estadísticos sofisticados. Lo que está en juego tras la puesta en marcha de las consultas es la extensión de su actividad hacia otros campos de acción y la movilización y permanencia de sus redes fuera del contexto electoral. Además, se trata, por un lado, de una apuesta organizacional interna, puesto que la asociación busca mantener por este medio el interés de los militantes entre dos elecciones y, por otro lado, esto forma parte del trabajo necesario para difundir su actividad ante la sociedad.

Para promocionar AC ante la sociedad fuera de los periodos electorales, se realizan diversas campañas de sensibilización. Éstas se presentan como herramientas de comunicación eficaces que combinan una dimensión lúdica y de formación, adoptan un tono más bien satírico, incluso caricaturesco, y se ilustran con varias imágenes. Estos materiales pueden ser de tipo audiovisual o documental, para que sean accesibles al mayor número de personas. El panfleto “iEs de a pollo, no de a huevo!” y el folleto “¡No es justo!” (véanse imágenes 1 y 2) son algunos ejemplos. En el transcurso de las campañas de "Juego limpio” y “No se vale!”, se produjeron y difundieron miles de carteles, folletos, calcomanías y panfletos con leyendas como éstas: "Participa para garantizar un juego limpio", "Con un juego limpio, México puede ganar", "Vota libre y en secreto". ${ }^{51}$

50 AAC, "Consulta Ciudadana del 26 de febrero...", p. 3.

${ }^{51}$ AAC, "Asamblea Nacional”, 30 de septiembre-1 de octubre de 1994, pp. 1920, y la serie de ocho folletos Observadores por un Juego Limpio, 1994. 


\section{IMAGEN 1}

¡Es de a pollo no de a huevo!
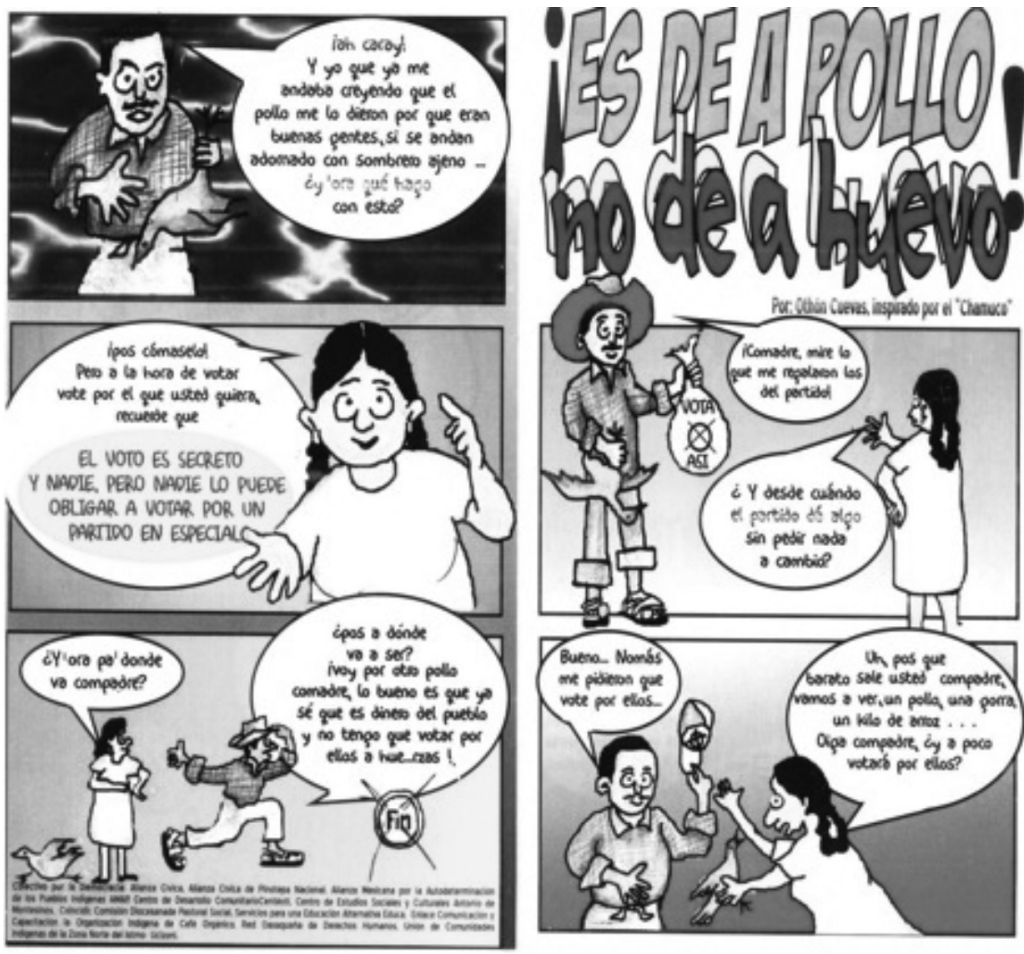

Los medios materiales y financieros empleados durante estas campañas por las Alianzas locales y sus responsables son modestos. En 1994, AC contó con el apoyo del gobierno federal para obtener espacios publicitarios en los medios: una cadena de televisión y algunos periódicos nacionales y locales respondieron al llamado del secretario de gobernación. ${ }^{52}$ Pero esto fue excepcional: la implementación de las campañas se basa principalmente en el trabajo de campo de los militantes y de las redes de periodistas. La amplitud de las campañas varía sensiblemente de una región a otra. En el estado de Jalisco, por ejemplo, varios responsables de Alianza local

\footnotetext{
52 AAC, "Asamblea Nacional”, 30 de septiembre-1 octubre de 1994, p. 19.
} 
son periodistas y universitarios, lo cual facilita la difusión del movimiento y sus actividades. Esta Alianza es una de las representaciones locales que permaneció activa durante la mayor parte de tiempo desde la fundación de la asociación (al menos hasta 2005). Por el contrario, en el estado de Aguascalientes, un antiguo responsable de la Alianza local nos relata las dificultades para darse a conocer y responder a las exigencias de la oficina central: "no se dan cuenta que no tenemos medios y que tenemos un trabajo aparte". ${ }^{53}$

\author{
IMAGEN 2 \\ ¡No se vale!
}

\title{
¿TE QUIEREN PRESIONAR PARA VOTAR?
}

Durante muchos afos, en tiempos de elecciones aparecen "promotores" y funcionarios que intentan amenazar. chantajear o comprar votos mediante presiones injustas e ilegales.

Dicen cosas como estas:

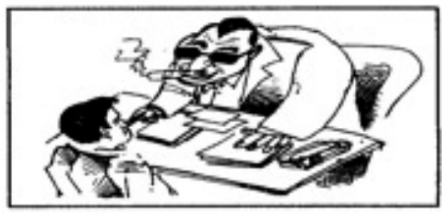

- Aquir erienes la miead del cheque por tu siembra. La otra mitad te la damos despues de las elecciones. Ya sabes por quien clenes gue vocar: ".

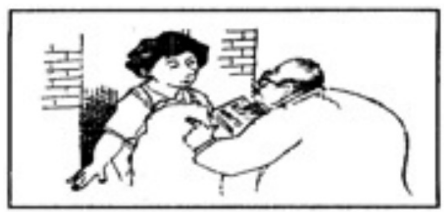

- "Como ya le dimos sus escricuras, ahora Ld. está comprometida a votar por el partido."

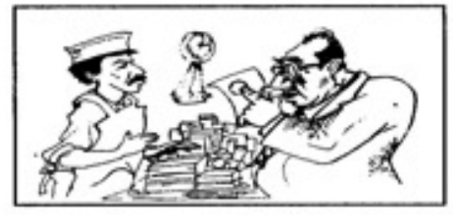

- "Para seguir vendiendo aqui, clone que votar por nuestro partido.".

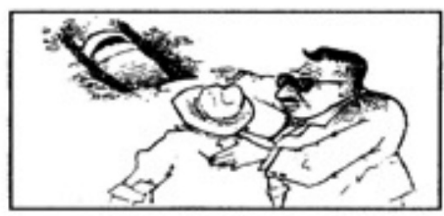

- "para poder concinuar la obra, necesicamos que voce por nuestro candidato."

53 Discusión informal con un antiguo responsable de la AC del estado de Aguascalientes. 
Las actividades sobre el involucramiento de los ciudadanos en la vida pública muestran claramente las dificultades que debe enfrentar AC para mantenerse activa con el paso del tiempo. En primer lugar, es necesario solucionar el problema de su financiamiento. Sus recursos provienen mayoritariamente del Fondo de Apoyo para la Observación Electoral y de fundaciones y organizaciones internacionales, principalmente estadounidenses, entre 1994 y 2000 , y están condicionados a la realización de actividades de control electoral. Para el resto de sus actividades, la asociación debe apoyarse en el trabajo voluntario de sus militantes y sus propios recursos. Se presenta luego el problema de la institucionalización de la observación electoral. Sus redes locales se vuelven cada vez más proclives a actuar de forma autónoma de la asociación, contribuyendo a la exacerbación de la competencia por la obtención de recursos financieros a causa de la multiplicación de asociaciones. Además, persiste el problema, no menos importante, de reformular el sentido de su acción una vez celebrada la importante reforma del sistema electoral de 1996, puesto que hasta ese entonces, su participación gira en torno a la democracia y la lucha por elecciones libres. A esto se suma el hecho de que en el año 2000, se celebró la alternancia política que acabó con 71 años de gobierno priísta. Finalmente, Alianza entra en una fase de fuerte desmovilización motivada, entre otras cosas, por la tentativa de ciertos miembros de transformarla en una Agrupación Política Nacional (APN) en 1997, con el propósito de participar en la competencia política y por la partida de muchos responsables de las Alianzas locales y de algunos de sus miembros fundadores hacia las instituciones públicas en plena transformación.

\section{Vigilar al gobierno}

El inicio de los años 2000 representa un giro en la historia de AC frente a los retos y transformaciones políticas y sociales planteados por la alternancia política. En este contexto, se toma la decisión de inscribir con mayor firmeza su lucha en los debates en torno al derecho a la información. La "transparencia" se vuelve un tema 
prioritario. El régimen político mexicano se caracteriza por un ejercicio del poder discrecional. El debate en este sentido lleva a poner sobre la mesa el problema del funcionamiento de las instituciones públicas y el desempeño de los funcionarios. Las campañas "Adopta a tu diputado" y "Para que los diputados sirvan" (véase cuadro 5) ilustran la manera en que Ac contribuye a este debate. Su

\title{
Cuadro 5
}

"Adopta a tu diputado" y "Para que los diputados sirvan"

\begin{abstract}
Estas campañas tienen como objetivo incitar a los militantes y ciudadanos a enviar sus demandas de información a las autoridades. La demanda de información dirigida al presidente de la República en 1995 tiene una carga simbólica fuerte, puesto que implica a la figura más emblemática del gobierno. ${ }^{a}$ Subsecuentemente, en distintos estados de la República se repite esta iniciativa: en Tabasco, en Guanajuato y en Jalisco, las demandas son dirigidas respectivamente al gobernador, al alcalde de Celaya y al secretario de gobernación. ${ }^{b}$ Por otra parte, otras campañas se interesan más precisamente en el funcionamiento cotidiano de una institución o desempeño de las actividades de los funcionarios o de los cargos de elección popular durante un tiempo relativamente largo (varios meses). Tal es el caso de la ambiciosa campaña "Poder ciudadano", que pretende definir y dar a conocer la "Agenda Nacional de la Sociedad Civil" sobre temas variados: economía, democracia, derechos sociales, seguridad, globalización y educación. ${ }^{c}$
\end{abstract}

a Véanse los siguientes documentos de la AAC: "Las violaciones al derecho a la información de los mexicanos", sin fecha; "Proyecto del texto de denuncia ante la CIDH", 1 de septiembre de 1997, y AAC, "Consejo Nacional”, informe, 3 de abril de 1995 .

b Véase J. M. Ramírez, "Ciudadanos bajo sospecha. El movimiento «Alianza Cívica» y el gobierno panista de Guadalajara. México, 1995-1999”, Sociedad civil, vol. 3, núm. 8, 2000, pp. 200-203.

c AAC, "Poder Ciudadano: Agenda Nacional de la Sociedad Civil", sin fecha.

propósito es hacer pública la información sobre los ingresos de los funcionarios y su patrimonio, cómo el dinero público se utiliza y el detalle de los presupuestos y organigramas de las instituciones públicas. La petición de información enviada a la Presidencia de la República acerca del salario del presidente, Ernesto Zedillo, y el 
ejercicio del presupuesto discrecional en 1995, fue particularmente importante, ya que fue el antecedente que dio lugar a la fundación del Grupo Oaxaca, compuesto de universitarios, militantes y periodistas. Este grupo elaboró el proyecto de ley sobre el acceso y el derecho a la información, que se convirtió en ley federal en 2002. ${ }^{54}$

Estas acciones contribuyen a abrir el debate sobre temas sensibles hasta entonces relegados, como los lazos entre el dinero, la ética y la política. Como sostienen Éric Phélippeau y Pascal Ragouet, en su trabajo sobre las cuentas financieras de las elecciones legislativas en Francia de marzo de 1993, las "fronteras entre dinero y política [están] en redefinición continua" y son objeto de debate. ${ }^{55} \mathrm{AC}$ retoma esta problemática como parte de su lucha, pero la trata desde la perspectiva del uso político del dinero público en los programas sociales, sobre todo en el ámbito de la salud ${ }^{56} \mathrm{o}$ de ayuda a la pobreza, ${ }^{57}$ donde se ataca la cuestión más general de la transparencia en la información de los programas sociales. ${ }^{58}$ Concretamente, se establece un protocolo de monitoreo de los programas sociales que, como en el caso de los dispositivos de participación directa, retoma las bases de la metodología desarrollada para la observación electoral. Como su propósito no es el mismo, este protocolo se vuelve una especie de protocolo de investigación para estudios especializados (véase cuadro 6) y es objeto de una publicación en la "Serie de guías para la supervisión ciudadana de las

54 "Ley Federal de Transparencia y Acceso a la Información Pública Gubernamental", Decreto de creación del Instituto Federal de Acceso a la Información Pública Gubernamental, sin fecha, p. 1. Este grupo también es el signatario de la Declaración de Oaxaca de 2001.

55 "Argent et politique. Une relecture sociologique des comptes financiers des législatives de mars 1993”, Revue française de sociologie, vol. 48, núm. 3, 2007, p. 551.

56 "L'Équité dans la santé: surveillance citoyenne de l'assurance populaire" y "La Surveillance de services de santé dans les zones à taux élevée de mortalité materne”, en 2009.

57 "La Transparence et la responsabilité politique: l'impact du programme de l'assurance populaire dans le District Fédéral”, en 2008.

58 "Le Taux de transparence des programmes sociaux", en 2005; "la Surveillance citoyenne de l'utilisation des programmes sociaux dans les contextes électoraux" y "les pratiques d'achat et de cooptation du vote par les acteurs politiques et gouvernementaux", entre 2008 y 2009. 
obligaciones gubernamentales". Las primeras experiencias de monitoreo de las instituciones enfrentan fuertes reticencias de parte de las autoridades políticas, obligando a AC a elaborar una estrategia jurídica que justifique la legalidad de las solicitudes y obligue a las autoridades a responder.

\section{Cuadro 6}

Los 10 puntos del protocolo de monitoreo de los programas sociales de AC

1) Definición de los objetivos y de la amplitud del monitoreo.

2) Investigaciones sobre el programa social.

3) Establecimiento de un diagnóstico sobre el estado del programa (logros y restricciones).

4) Elaboración del material de investigación: guías de entrevista y de observación, cuestionarios, etc.

5) Formación.

6) Trabajo de campo.

7) Sistematización y análisis de datos.

8) Preparación de informes y propuestas.

9) Publicación de resultados.

10) Intercambio con las autoridades. ${ }^{a}$

a Del AAC, véanse Manual de contraloría social: monitoreo ciudadano a programas sociales federales, 2008, y "Proyectos de observación electoral 2008-2009. Alianza Cívica A. C. Informe final”, 2009.

Alianza Cívica reivindica un expertise electoral propio basado en su trabajo de observación electoral. Sin embargo, este expertise conjuga a la vez la experiencia del trabajo de campo en diferentes ámbitos (electoral, políticas sociales e institucional), una metodología de acción aplicable a problemáticas diferentes y una estrategia de comunicación que difunda la legalidad de sus acciones y el rigor científico que éstas conllevan. La principal innovación de AC respecto a otros movimientos mexicanos que lucharon también por las elecciones es que por medio de sus acciones cuestiona tanto las maniobras políticas y administrativas como las electorales y 
actúa en nombre de la legalidad, apoyándose en evidencias concretas e inscribiendo sus acciones en el registro de la "vigilancia", el "control" y la "observación". En el mundo, su experiencia se convierte en referente en materia de observación electoral para las ONGs locales latinoamericanas y para ciertas organizaciones internacionales. Durante nuestra estancia en la oficina de la "sociedad civil" de la OEA, muchas veces nos hicieron el comentario: "hablas de LA Alianza Cívica". ${ }^{59}$ Se solicita frecuentemente a sus militantes para compartir su experiencia o formar redes de observadores. Respecto a sus homólogos latinoamericanos, AC logró adaptar su actividad a las evoluciones y retos impuestos por el contexto político, conservando una dimensión contestataria con la activación puntual de sus redes localmente.

\section{UTILIZAR EL DERECHO PARA HACERSE ESCUCHAR}

El desplazamiento efectuado por AC de la lucha por la honestidad de las elecciones al cuestionamiento del desempeño de las instituciones, no siempre fue bien recibido por los responsables políticos. Cuestionar abierta y directamente sobre la manera en la que se ejerce el poder es una forma de someter al escrutinio público cuestiones sensibles dada la historia autoritaria de este país, como la confianza en las instituciones y la autoridad política. Pero sobre todo, el debate acerca de este tipo de temas puede representar un obstáculo en la evolución de las carreras políticas de funcionarios y candidatos a cargos de elección popular. Como lo muestra concretamente el episodio sobre el conflicto político en Jalisco presentado al inicio de este artículo, en el cual se pone en juego tanto la legitimidad de una institución pública, el INE, emblemática del proceso de democratización de este país, como la de un gobernante y funcionario público en pleno ejercicio de sus funciones, respectivamente el gobernador y el magistrado del estado en cuestión.

59 Notas de trabajo de campo durante una estancia en la Organización de Estados Americanos (OEA) de junio a septiembre de 2005, en Washington, tras una conversación informal con el responsable de la sociedad civil de ese entonces. 
Si la observación electoral se inscribe en una larga historia de luchas que aclaman la reforma del sistema electoral, exigir a los gobiernos que rindan cuentas de su desempeño como responsables de las instituciones es una reivindicación reciente que conllevará la movilización de otros tipos de recursos.

Ante el fracaso de varias solicitudes de información presentadas por AC, se pone en marcha una estrategia jurídica basada en demandas y denuncias. Diferentes trabajos universitarios se han interesado en la problématica del uso del derecho para resolver los conflictos políticos, sobre todo en el caso de países que enfrentan un proceso de cambio de régimen. ${ }^{60} \mathrm{Si}$ AC se sirve del derecho como recurso para presionar y obligar a los gobernantes a rendir cuentas de sus acciones, esto le permite también establecerse como un espacio de aprendizaje, en el cual sus militantes adquieren diversas competencias jurídicas y electorales que les permite ser reconocidos como "expertos electorales".

\section{Movilizarse, utilizando el derecho}

Luego de que la Presidencia de la República rechazara responder a la demanda de información presentada en 1995 sobre el salario del presidente y las líneas presupuestarias discrecionales, AC idea una estrategia jurídico-política. Para ello, se apoya en un equipo de juristas especializados en derecho electoral, ${ }^{61}$ quienes, en coordinación con los militantes, definen y redactan un argumento central, además del texto de la demanda. Estos juristas cuentan con experiencia profesional en instituciones electorales y una formación en derecho por universidades nacionales o extranjeras, los cuales se inscriben en la generación de notables del derecho y de los "Chicago boys", analizada por Yves Dézalay y Bryant Garth, en su obra arriba citada. Algunos de ellos participaron incluso como consejeros durante las reformas electorales de finales del siglo $\mathrm{xx}$

${ }^{60}$ Véanse, por ejemplo, J. Heurtaux, "L'amont et l'aval d'une loi électorale", RFSP, vol. 63, núm. 3, 2013, pp. 519-544, y L. Israël, op. cit.

${ }^{61}$ Véase AAC, "Proyecto de denuncia ante la CIDH", ya citado. 
y expresan sus afinidades por la lucha con la defensa de los derechos políticos y electorales.

Esta estrategia se lleva a cabo en dos tiempos. En primer lugar, AC presenta una demanda con base en los artículos 6 y 8 de la Constitución sobre los derechos de petición y de información. El argumento central es que la información solicitada es de interés público. Aunque la quinta Corte administrativa falla a favor de los ciudadanos y de AC, la información brindada por la presidencia es imprecisa a pesar de que se apela en varias ocasiones. ${ }^{62}$ Para apelar la decisión, se modificó el argumento y se precisó que aunque la respuesta emitida por la presidencia respete el derecho de petición, viola el derecho a la información. El cambio de argumento define la segunda fase de la estrategia. Para ejercer una mayor presión sobre el gobierno, AC decide acudir a la instancia superior en materia jurídica y, como último recurso, apela a las instancias internacionales competentes. Tal decisión, eminentemente estratégica y motivada por los lazos con las altas esferas internacionales de militantes y juristas, permite denunciar la violación de los derechos ante los organismos internacionales, principalmente estadounidenses, que financian las asociaciones de defensa de los derechos humanos como AC. La imagen internacional del país se utiliza nuevamente como un medio para ejercer presión sobre el gobierno. Esto en un contexto de aceleración de intercambios económicos internacionales y aumento de ayudas para el desarrollo, condicionadas por la existencia de "buenas prácticas" de gobierno según los principios democráticos, entre los cuales la defensa de los derechos humanos está en el centro del debate. Esta estrategia jurídica se repite en los estados y municipios donde persiste una cierta reticencia de los gobernantes a las demandas de información de Ac. Es en estos niveles de gobierno en los que se registra un rechazo categórico a este tipo de solicitudes. ${ }^{63}$

Esta estrategia se acompaña de una campaña de comunicación para hacer accesibles los argumentos jurídicos y demostrar que es

${ }^{62}$ Cf. AAC, Boletín especial, núm. 4, 21 de junio de 1996.

${ }^{63}$ Véase AAC, "Consejo Nacional", ya citado. 
posible exigir de los gobiernos que rindan cuentas. El trabajo de campo durante esta fase consiste en que los militantes se apropien de los argumentos jurídicos para explicarlos al mayor número de personas, como lo subraya un miembro del Consejo Nacional de la AC: se deben "usar con moderación [para militantes y ciudadanos] los argumentos jurídicos, siempre complicados y pesados". ${ }^{64}$

Esta estrategia se ejecuta igualmente en el caso de otro tipo de problemas. Por ejemplo, en 1996, cuando se reconoce el "juicio para la protección de los derechos político-electorales" 65 como un recurso que pueden presentar los ciudadanos, se intenta por este medio impugnar los resultados de las elecciones, a pesar de que en principio sólo los partidos políticos están facultados para ello. Las acciones legales presentadas por los ciudadanos y AC son una estrategia que cuestiona la legitimidad de las reformas y los resultados electorales, pues con ellas se denuncian las infracciones a la ley. Estas acciones rara vez tienen éxito. Sin embargo, estas experiencias dan a los militantes la posibilidad de aprender a traducir su causa utilizando un lenguaje jurídico y desarrollar competencias procesales en materia electoral e institucional. ${ }^{66}$ Los esfuerzos y el reconocimiento adquirido por Ac, en lo que toca a la observación electoral, contribuyen a que los militantes se conviertan en "expertos de las elecciones y de las instituciones". El uso del derecho en este caso resulta a la vez una fuente de legitimidad, un medio de argumentación y un espacio de aprendizaje.

\section{Alianza Cívica y sus expertos electorales}

El reconocimiento de los militantes como "expertos electorales" se inscribe en el proceso de valoración de los recursos asociativos especializados como competencias profesionales, así como en la

${ }^{64} I d$.

${ }^{65}$ L. Córdova, "La reforma electoral y el cambio político en México", en Daniel Zovatto y José Orozco Henríquez (dirs.), Reforma política y electoral en América Latina 1978-2007, México, UNAM-IDEA, 2008, p. 668.

${ }^{66}$ Véase Alexis Spire y Katia Weinfield, "Le tribunal administratif : une affaire d'initiés ?”, Droit et société, vol. 3, núm. 79, 2011, pp. 689-713. 
evolución de los criterios de las condiciones de reclutamiento en las instituciones públicas de finales de los años noventa. Durante esta época, las competencias especializadas y la imparcialidad de los candidatos se reconocen como criterios importantes de reclutamiento. El reconocimiento de los militantes de AC como especialistas de cuestiones electorales e institucionales y actores independientes de los actores partidistas, hace más probable y facilita su contratación. Su participación en esta asociación comprueba que poseen un conocimiento especializado sobre las reglas electorales y las instituciones, un cierto capital militante y procedimental, así como un conocimiento empírico en el ámbito electoral e institucional. Pero esto les permite además revalorar su compromiso en cuanto que "actores ciudadanos", es decir actores que se presentan como aquellos que cuentan con un compromiso político y social basado en su interés por la vida pública y su capacidad de mantener una cierta independencia de los partidos políticos. Es de esta forma, por ejemplo, que Alfredo Figueroa, fundador de AC, se desempeña en varias ocasiones como consejero del Instituto Federal Electoral después de dejar la asociación:

Desde los años noventa, Alfredo Figueroa participa activamente en asociaciones que luchan por la democracia y las cuestiones electorales, entre ellas AC, en 1994, y el Comité Conciudadano para la Reforma Electoral, en 2007. Tras dejar AC, hacia finales de los años noventa, el doctor en sociología política se integra a la Universidad de Puebla como profesor investigador, donde desarrolla diversos proyectos de investigación sobre las instituciones públicas. Su partida de AC marca el inicio de su carrera como consultor en despachos especializados en asuntos públicos y editorialista de distintos periódicos. Gracias a su formación, a su experiencia de consejero electoral del IFE en Puebla (en 2002-2003 y 2005) y al apoyo obtenido de parte de varias organizaciones de la sociedad civil y del sector académico, se convirtió en uno de los 11 consejeros nacionales del IFE en 2008. Su experiencia en AC le proporcionó la oportunidad de desarrollar su interés por las cuestiones electorales y especializarse en ese ámbito. Durante sus diversos mandatos de consejero electoral, 
participa activamente en las comisiones especializadas y la dirección nacional de formación de esta institución. ${ }^{67}$

Los militantes que dejan la organización para integrar las instituciones públicas, como Alfredo Figueroa, asumen con frecuencia responsabilidades ligadas a la organización de las elecciones, al acceso a la información o a las relaciones entre el gobierno y la sociedad civil. Por ejemplo, dos coordinadores del proyecto "Poder ciudadano" integran el gobierno federal en 2000 durante la alternancia política. Uno de ellos asume la responsabilidad de la dirección del programa de ayuda a la pobreza más grande de América Latina (Oportunidades), mientras que el otro se desempeña como responsable de los vínculos entre el gobierno y la sociedad civil. ${ }^{68}$ Muchos son los militantes que dejan AC en aquella época. Durante nuestro trabajo de campo entre 2004 y 2009, sobre las trayectorias militantes, afectivas y profesionales de los miembros de AC, observamos que el $32 \%$ de los encuestados ocuparon un cargo en el IFE durante o después de su participación en AC, contra el 25\% en otra institución pública. Esta tendencia se confirma en el estudio realizado por J. Alonso y A. Aziz, quienes apuntan que en 1999 al menos 25 de 31 consejos electorales locales provenían de las redes de AC y de los organismos de defensa de los derechos humanos. ${ }^{69}$ Es innegable que estos militantes siguen apoyando a AC desde sus cargos en las diversas instituciones y que eso contribuye a que la asociación pueda mantenerse activa con el paso del tiempo. Este apoyo es sobre todo simbólico. Con frecuencia se solicita a la organización

${ }^{67}$ Información obtenida a partir de investigaciones electrónicas, todas consultadas el 9.III.2009: www.InstitutoFederalElectoralConsejerosElectorales_AlfredoFigueroa.mht; www.soc.culture.mexicanMinistroGenaroDavidGóngoraPimente 1_o_AlfredoFigueroa(porelPRD)-soc_culture_mexicanGoogleGroupes.mht; www. cencos.org/organizacionescivilesaapoyancandidaturadeAlfredo FigueroaparaCon sejerodelIFECentroNacionaldeComunicaciónSocialAC.mht; www.eluniversal.com. mx/Van112aspirantesaIFE,perosólohay10mujeres-EIUniversal-México_AlfredoFigueroa.mht; periodicodigital.com.mx/políticaAlfredoFigueroa,nuevointegranted elIFE-PeriódicoDigitalPuebla-Noticiasparapoblanosglobales.mht

${ }^{68}$ AAC, "Poder Ciudadano: minuta de la coordinación", 9 de agosto de 2000, p. 2.

${ }^{69}$ Campo electoral, espacios autónomos y redes, México, CIESAS-IIHS, 2005. 
intervenir en los proyectos de evaluación y de formación que organiza el Instituto Nacional de Desarrollo Social (INDESOL), organismo responsable de la cooperación del gobierno con la sociedad civil, en los grupos de trabajo previo a una reforma electoral.

Sus miembros justifican algunas veces su partida con el argumento de que al actuar desde el interior de las instituciones contribuirán a consolidar el cambio democrático para terminar con las prácticas autoritarias de los gobiernos priístas. El nuevo siglo marca una etapa nueva para AC. Ésta ya no representa aquel movimiento que, reuniendo actores de posiciones políticas diversas, actúa principalmente en nombre de la defensa de los derechos políticos y electorales; se erige entonces como una asociación especializada que actúa sobre todo en espacios institucionales, ejerciendo actividades de orden consultivo. Hoy en día, esta asociación que cuenta con el reconocimiento histórico de garante de las elecciones y las instituciones, se posiciona como un actor crítico de los límites de los avances en materia electoral e institucional que ella misma celebró a finales del siglo pasado. Aunque en principio AC dirige su crítica a la normalización de las maniobras políticas y electorales priístas, el pluralismo político que se instaura en este país la obliga a replantear su posición: la persistencia de ese tipo de maniobras concierne tanto al PRI, como a los demás partidos políticos.

\section{Conclusión}

Tras la larga historia de luchas por el establecimiento de un gobierno democrático en México, los avances siguen siendo cuestionados a causa del contexto de violencia y desigualdad en el cual se encuentra el país. Pensemos en el reciente caso de la desaparición de 43 estudiantes en Ayotzinapa, Guerrero, en 2015. Aunque hasta inicios de este siglo los avances democráticos se referían sobre todo a las transformaciones en el ámbito electoral, el análisis del repertorio de acciones de AC y el conflicto político suscitado en Jalisco, en 2015, muestran sus límites. Este conflicto político local es particularmente interesante, porque se trata de un estado donde la 
alternancia política tuvo lugar relativamente temprano respecto a otros estados en los cuales no se ha celebrado una alternancia, como Durango, gobernado desde hace casi un siglo por el PRI. Lo acontecido en Jalisco, que pudo haber sucedido en cualquier otro estado e implicado a otros actores, muestra cómo la distorsión del principio de la observación electoral puede subrayar ciertos progresos, es decir a pesar de que el objetivo de esta actividad (elecciones celebradas con respeto de las reglas electorales) se haya tergiversado, el hecho de que este conflicto haya salido a la luz pública nacional representa en sí un avance, puesto que esto hubiera sido impensable algunas décadas atrás.

A pesar de los esfuerzos de AC y de otros actores por legitimar las elecciones y la reforma del sistema electoral y las instituciones mediante la observación electoral, ni los equilibrios políticos ni las prácticas políticas parecen haber sido fundamentalmente trastocados. Como lo demuestra la impugnación de los resultados de la elección presidencial de 2006 que, luego de una larga batalla jurídica, conlleva el recuento de votos en $9.1 \%$ de las casillas electorales o incluso la reforma una vez más, en 2012, del IFE. Denunciar las desigualdades entre candidatos durante la competencia política es una manera de señalar los obstáculos que persisten para la institución de un régimen democrático: el ejercicio discrecional del poder, la corrupción y las violaciones de los derechos individuales. Si AC encarna una forma distinta de hacer política fundada en métodos basados en pruebas y en el recurso al derecho para legitimar sus acciones, las prácticas políticas en este país siguen estando impregnadas de actitudes autoritarias tan antiguas como el PRI. Concluimos este artículo, señalando la importancia y el interés de prolongar esta reflexión, en la perspectiva de un análisis centrado en la normalización de las prácticas de manipulación electoral y política que cuestionan, aún hoy en día, el avance democrático en México. Una pista podría ser, por ejemplo, realizar un estudio sobre la historia social de la elaboración de las reglas electorales en este país. 


\section{BibliogRAFíA}

AAC: Archivos de la Alianza Cívica, "Las elecciones en Yucatán. Informe preliminar de la observación electoral, Frente Cívico Familiar-mujeres yucatecas en lucha por la democracia-Grupo Indignación”, 1993.

—, "2 ${ }^{\circ}$ plebiscito ciudadano sobre la reforma política del Distrito Federal", 1993.

-, "Asamblea Nacional", 30 de septiembre-1 de octubre de 1994.

, "Campos de la observación 2. Observación de campañas políticas", 1994.

—, "Campos de la observación 5. Propuesta de análisis de contenido electoral de medios de comunicación”, 1994.

—, Observadores por un Juego Limpio, 1994.

_ , "Consejo Nacional", informe, 3 de abril de 1995.

—, "Asamblea Nacional”, 14 de diciembre de 1996.

—, Boletín, núm. 1, mayo-junio, 1996.

—_, "Informe de la observación previa a la jornada electoral y evaluación de las condiciones con que se llegan a las elecciones”, 1996.

—, "Proyecto del texto de denuncia ante la CIDH", 1 de septiembre de 1997.

, "Poder Ciudadano: minuta de la coordinación", 9 de agosto de 2000.

—_ "Guía de observación de la calidad de la jornada electoral", julio de 2006.

— Manual de contraloría social: monitoreo ciudadano a programas sociales federales, 2008.

—, "Proyectos de observación electoral 2008-2009. Alianza Cívica A. C. Informe final”, 2009.

_, "Consulta ciudadana del 26 de febrero. Informe final", sin fecha.

, "Informe especial sobre la observación integral de los procesos electorales de Guanajuato y Yucatán de 1995”, sin fecha.

— , "Informe final del campo de observación, compra y coacción del voto", Alianza Cívica/Observación 94, sin fecha.

_- "Las violaciones al derecho a la información de los mexicanos", $\sin$ fecha. fecha. 
Aguayo Quezada, Sergio, "Electoral Observation and Democracy in Mexico", en Kevin Middlebrook (dir.), Electoral observation and democratic transitions in Latin America, San Diego, Center for U.S.-Mexican Studies, University of California, 1998, pp. 167-186.

Alonso, Jorge y Alberto Aziz, Campo electoral, espacios autónomos y redes, México, CIESAS-IIHS, 2005.

Aziz, Alberto, "Chihuahua y los límites de la democracia electoral", Revista Mexicana de Sociología, vol. 49, núm. 4, 1987, pp. 159-226.

Barraza, Leticia e Ilán Bizberg, "El Partido Acción Nacional y el régimen político mexicano", Foro Internacional, vol. 31, núm. 3, 1991, pp. 418445.

Beigbeder, Yves, International monitoring of plebiscites, referenda and national elections self-determination and transition to democracy, Dordrecht, Nijhoff, 1994.

Benítez Manaut, Raúl, "La onu en México. Elecciones presidenciales de 1994”, Foro Internacional, vol. 36, núm. 3, 1996, pp. 533-565.

Carothers, Thomas, "The Observers Observed", Journal of Democracy, vol. 8, núm. 3, 1997, pp. 17-31.

Combes, Hélène, De la politique contestataire à la fabrique partisane, tesis, París, Université Paris 3, 2004.

Córdova, Lorenzo, "La reforma electoral y el cambio político en México", en Daniel Zovatto y José Orozco Henríquez (dirs.), Reforma política y electoral en América Latina 1978-2007, México, UNAM-IDEA, 2008.

Covarrubias, Ana, "El problema de los derechos humanos y los cambios en la política exterior”, Foro Internacional, vol. 39, núm. 4, 1999, pp. 429-452.

Déloye, Yves y Olivier Ihl, L'acte de vote, París, Presses de Sciences Po, 2008.

Dézalay, Yves y Bryant Garth, La mondialisation des guerres de palais, París, Seuil, 2002.

Donno, Daniela, Defending Democratic Norms, Oxford, University Press, 2013.

Dompnier, Nathalie, La clef des urnes, tesis, IEP de Grenoble, 2002.

-, "La mesure des fraudes électorales. Difficultés méthodologiques et enjeux politiques", Histoire $\mathcal{E}$ Mesure, vol. 22, núm. 1, 2007, pp. 123-144.

Elklit, Jorgen y Palle Svensson, "What makes elections free and fair?", Journal of Democracy, vol. 8, núm. 3, 1997, pp. 32-46. 
"Entrevista con Delia Tena, antigua militante de la AC", 22 de febrero de 2006.

"Entrevista con Carlos Peralta", 2 de marzo de 2006.

"Entrevista con S. Aguayo Quezada, fundador de la AC", 12 de marzo de 2008.

"Entrevista con uno de los responsables de la primera misión del PNUD en México", 14 de marzo de 2008.

Fillieule, Olivier, "Tombeau pour Charles Tilly Répertoires, performances et stratégies d'action”, en Éric Agrikoliansky, Isabelle Sommier y Olivier Fillieule (dirs.), Penser les mouvements sociaux, París, La Découverte, 2010, pp. 77-99.

Flores, Guillermina, Para una pedagogía de la educación ciudadana, tesis, México, Universidad Intercontinental, 1998.

Garrigou, Alain, Histoire sociale du suffrage universel en France 1848-2000, París, Seuil, 2002.

Gaïti, Brigitte y Liora Israël, "Sur l'engagement du droit dans la construction des causes", Politix, vol. 16, núm. 62, 2003, pp. 17-30.

Guilhot, Nicolas, The Democracy Makers, Columbia, University Press, 2005.

Hevia de la Jara, Felipe, La contraloría social mexicana: participación ciudadana para la rendición de cuentas, México, CIESAS-IIHS, 2006.

Heurtaux, Jérôme, "L'amont et l'aval d'une loi électorale", RFSP, vol. 63, núm. 3, 2013, pp. 519-544.

Huu Dong, Nguyen y David Recondo, "L'onu, artisan du processus électoral”, Critique internationale, núm. 24, 2004, pp. 159-176.

Hyde, Susan, The pseudo-democrat's dilemma why election observation became an international norm, Londres, Cornell University Press, 2011.

IEPC: Instituto Electoral y de Participación Ciudadana, "Lineamientos para la observación electoral. Proceso electoral local 2008-2009”, sin fecha.

IFE, "Fondo de Apoyo para la Observación Electoral", sin fecha.

"La justice comme espace politique. Trois études de cas: Israël, Inde, Argentine”, Droit et société, vol. 3, núm. 55, 2003.

Lehoucq, Fabrice, "Electoral Fraude: Causes, Types, and Consequences", Annual Review of Political Science, núm. 6, pp. 233-256.

"Ley Federal de Transparencia y Acceso a la Información Pública Gubernamental", Decreto de creación del Instituto Federal de Acceso a la Información Pública Gubernamental, sin fecha. 
Liora, Israël, L'arme du droit, París, Presses de Sciences Po, 2009.

Loaeza, Soledad, "El papel político de las clases medias en el México contemporáneo”, Revista Mexicana de Sociología, vol. 45, núm. 2, 1983, pp. 407-439.

—. Clases medias y política en México. La querella escolar, 1959-1963, México, El Colegio de México, 1988.

"Manda en campaña papá... incómodo", Reforma, 13 de abril de 2015, en http://ntrzacatecas.com/2015/04/13/manda-en-campana-papa-incomodo/

Marti I Puig, Salvador, Reynaldo Yunuen Ortega Ortiz y María Fernanda Somuano Ventura, La democracia en México. Un análisis a 10 años de la alternancia, Barcelona, Bellaterra, 2011.

McCoy, Jennifer, "Monitoring and Mediating Elections during Latin American Democratization", en Kevin Middlebrook (dir.), Electoral observation and democratic transitions in Latin America, San Diego, Center for U.S.-Mexican Studies, University of California, 1998.

Meyer, Lorenzo, Nuestra tragedia persistente. La democracia autoritaria en Mexico, México, Debate, 2013.

Nevitte, Neil y Santiago Canton, "The Role of Domestics Observers", Journal of Democracy, vol. 8, núm. 3, 1997, pp. 47-61.

Olvera, Alberto, Movimientos sociales prodemocráticos, democratización y esfera pública en México: el caso de Alianza Cívica, Veracruz, Universidad, 2001.

-, "Movimientos sociales prodemocráticos, democratización y esfera pública en México: el caso de Alianza Cívica”, en Alberto Olvera (coord.), Sociedad civil, esfera pública y democratización en América Latina: México, México, Universidad Veracruzana-Fondo de Cultura Económica, 2003, pp. 351-409.

Ortega Ortiz, Reynaldo Yunuen, Movilización y democracia: España y México, México, El Colegio de México, 2008.

"Papá de Aristóteles invita a cometer actos ilícitos durante las elecciones", grabación, 13 de abril de 2015, en https:/ /www.youtube.com/watch? $\mathrm{v}=\mathrm{gl} \_$FwpnPgEs

Phélippeau, Éric y Pascal Ragouet, "Argent et politique. Une relecture sociologique des comptes financiers des législatives de mars 1993”, Revue française de sociologie, vol. 48, núm. 3, 2007. 
Pozas, Ricardo, "La observación electoral: una modalidad de la militancia ciudadana”, Revista Mexicana de Sociología, vol. 59, núm. 2, 1997, pp. 23-40.

Quintana, Rubén, Movimientos populares en Chihuahua, Ciudad Juárez, Universidad Autónoma de Ciudad Juárez, 1991.

Ramírez, Juan Manuel, "Movimientos ciudadanos y democracia: el caso de Alianza Cívica”, en Jorge Alonso y Juan Manuel Ramírez (dirs.), La democracia de los de abajo en México, México, La Jornada-CIIH, 1997, pp. 29-52.

—_ "Ciudadanos bajo sospecha. El movimiento «Alianza Cívica» y el gobierno panista de Guadalajara. México, 1995-1999”, Sociedad civil, vol. 3, núm. 8, 2000, pp. 183-211.

Santa-Cruz, Arturo, "Monitoring Elections, Redefining Sovereignty: The 2000 Peruvian Electoral Process as an International Event”, Journal of Latin American Studies, vol. 37, núm. 4, 2005, pp. 739-767.

- Mexico-United States Relations, Londres-Nueva York, Routledge, 2012.

Spire, Alexis y Katia Weinfield, "Le tribunal administratif: une affaire d'initiés?", Droit et société, vol. 3, núm. 79, 2011, pp. 689-713.

Stevens, Evelyn P., "Legality and Extra-Legality in Mexico", Journal of Interamerican Studies and World Affairs, vol. 12, núm. 1, 1970, pp. 62-75.

Treviño Rangel, Jorge, "Las ong de derechos humanos y la redefinición de la soberanía del Estado Mexicano", Foro Internacional, vol. 44, núm. 3, 2004, pp. 509-539.

\section{APÉNDICE}

\section{Metodología}

Nuestro análisis adopta un enfoque sociohistórico y se basa en tres tipos de materiales:

1. Los archivos no públicos de Ac, conservados en la oficina central de la asociación. Éstos fueron analizados primeramente por nosotros (1994-2008). Obtuvimos la autorización para ello, luego de presentar una solicitud al director de la asociación, en la cual se explicó el propósito de la investigación y se justificó el interés científico 
de acceder a estos materiales. Los archivos están disponibles bajo solicitud para los investigadores interesados en el estudio de esta organización.

2. Entrevistas semiestructuradas con antiguos y actuales militantes de AC sobre su trayectoria militante, afectiva y personal. Realizadas entre 2006 y 2009 ( N=62), éstas tuvieron una duración de entre 45 y 145 minutos (ante la incomodidad de varios entrevistados frente a la grabación, en diversas ocasiones prolongamos las entrevistas fuera de grabación y esto algunas veces durante varias horas). Además, sostuvimos entrevistas informales con responsables institucionales nacionales (del IFE) e internacionales (de la OEA), las cuales se consideraron como material informativo.

3. Observaciones etnográficas durante una estancia en la oficina de la "Sociedad civil" de la Organización de Estados Americanos (oEA) de junio a septiembre de 2005 en Washington y una estancia en la oficina central de AC entre enero y marzo de 2008. Las observaciones realizadas en la oEA nos permitieron tener un mejor conocimiento acera de las dinámicas y prácticas de los donadores internacionales para confrontar los trabajos existentes al respecto, mientras que el acceso a los archivos fue central para la investigación. Organizamos y clasificamos nosotros mismos los documentos (minutas de reuniones, correspondencias, materiales producidos por la AC, informes, etc.). Por este material pudimos observar la transformación del movimiento en una estructura cada vez más jerarquizada y especializada y menos centrada en la lucha por la democracia. Asimismo, comprendimos mejor la posición intermedia que ocupa AC respecto a los actores, al participar en la competencia política, el gobierno y los ciudadanos.

Por la diversidad de fuentes de información recolectadas y analizadas, fue posible entender las evoluciones del movimiento durante un tiempo relativamente largo. 